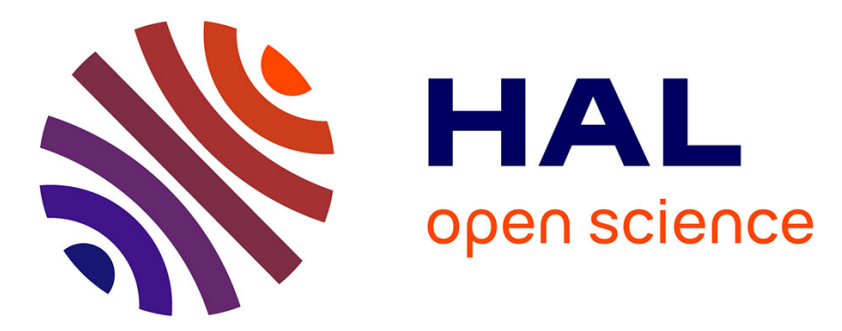

\title{
Innovative, non-contact wide field imaging of corneal endothelium
}

\author{
Samuel Etienne, Giacomo Pataia, Nicolas Naigeon, Aurelien Bernard, Zhiguo \\ He, Philippe Gain, Gilles Thuret, Jean-Charles Pinoli, Yann Gavet
}

\section{- To cite this version:}

Samuel Etienne, Giacomo Pataia, Nicolas Naigeon, Aurelien Bernard, Zhiguo He, et al.. Innovative, non-contact wide field imaging of corneal endothelium. Twelfth international conference on quality control by artificial vision - QCAV 2015, Le2i - Laboratoire Electronique, Informatique et image; IUT Le Creusot Centre Universitaire Condorcet, Jun 2015, Le Creusot, France. pp.9534-15, $10.1117 / 12.2182748$. emse-01258666

\section{HAL Id: emse-01258666 \\ https://hal-emse.ccsd.cnrs.fr/emse-01258666}

Submitted on 19 Jan 2016

HAL is a multi-disciplinary open access archive for the deposit and dissemination of scientific research documents, whether they are published or not. The documents may come from teaching and research institutions in France or abroad, or from public or private research centers.
L'archive ouverte pluridisciplinaire HAL, est destinée au dépôt et à la diffusion de documents scientifiques de niveau recherche, publiés ou non, émanant des établissements d'enseignement et de recherche français ou étrangers, des laboratoires publics ou privés. 


\title{
Innovative, non-contact wide field imaging of corneal endothelium
}

\author{
Aberra Guebrou S. ${ }^{a}$, Pataia G. ${ }^{b}$, Naigeon N. ${ }^{b}$, Bernard A. ${ }^{b}$, He Z. ${ }^{b}$, Gain P. ${ }^{b}$, Thuret G. ${ }^{b, c}$, \\ Pinoli J.-C. ${ }^{a}$ and Gavet Y. ${ }^{a}$ \\ ${ }^{a}$ Laboratoire Georges Friedel UMR 5307, Mines Saint-Étienne, 158 Cours Fauriel, 42023 \\ Saint-Étienne cedex 2, France; ${ }^{b}$ Corneal Graft Biology, Engineering and Imaging Laboratory, \\ EA2521, Federative Institute of Research in Sciences and Health Engineering, Faculty of \\ Medicine, Jean Monnet University; \\ ${ }^{c}$ Institut Universitaire de France, Paris.
}

\begin{abstract}
In this paper, we investigated the possibility of getting wide-field images of corneal endothelium for patients. An optical set-up coupled to a numerical reconstruction based on Structured Illumination Mircoscopy (SIM) has been developped in order to isolate the tiny volume wich contains the endothelial mono-layer found at the inner surface of the cornea. At this moment, this imaging system seems compromised for patients and futhur refinement are investigated for stored humans corneas banks.
\end{abstract}

Keywords: Corneal endothelium, Structured Illumination Microscopy, Specular microscope, Wide-Field Imaging, Patient diagnosis, Ophtalmology

\section{INTRODUCTION}

Cornea is the window of the eye through which the light comes in (see Fig. 1(a)). It is located in front of the eyeball. Its transparency is permanently regulated by a simple thin cellular monolayer found at the inner surface of the cornea called corneal endothelium.

Endothelium appears as a mosaic of hexagonal shaped cells of about $20 \mu \mathrm{m}$ diameter and $4 \mu \mathrm{m}$ thick (Fig. 1(b) shows an endothelium observed with a specular microscope). It regulates stromal hydration with numerous active ion transporters. Indeed, a relative dehydratation is necessary to maintain stroma transparency and then a good visual function.

(a)

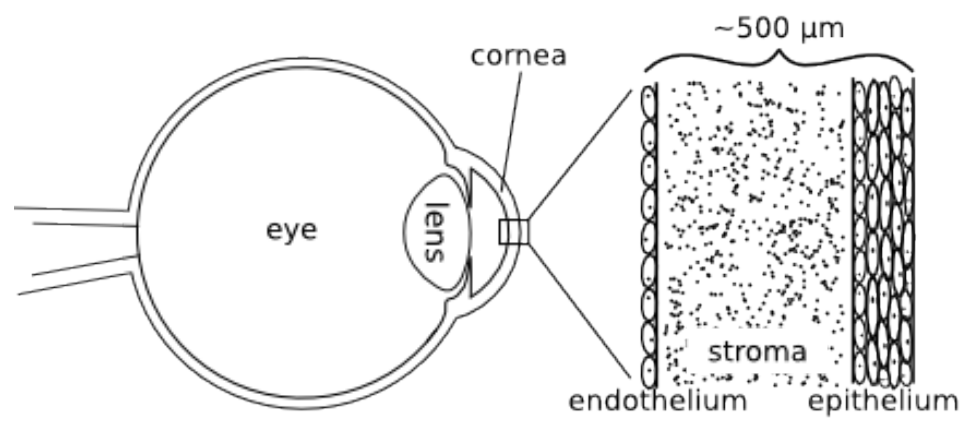

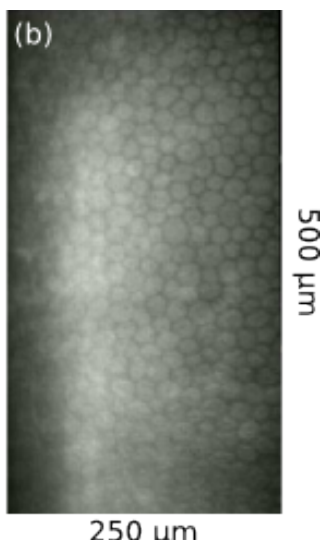

능

Figure 1. (a) Human eye. A local zoom on the cornea is made. The three main parts are shown: eptithelium, stroma and endothelium. (b) Image of an in-vivo corneal endothelium obtained with a non-contact specular microscope.

Further author information: (Send correspondence to G. Y.: E-mail: gavet@emse.fr.) 
Corneal endothelial cells do not regenate, so lost cells are never replaced. Nevertheless, mosaic intigrity is conserved with migration, enlargement and deformation of cells. With time, cornea knows a decrease of its endothelial cells density (ECD) and morphological changes. In physiological condition, due to the high ECD reserve $\left(\approx 3000\right.$ cells per $\left.\mathrm{mm}^{2}\right)$ and the low age related cellular loss $\left(\approx 0,5 \%\right.$ per year $\left.{ }^{1}\right)$, pahological threshold below which leaves an oedematous opaque cornea is never reached $\left(<500\right.$ cells $\left./ \mathrm{mm}^{2}\right)$. On the other hand, various injuries (cataract surgery, myopic correction) or several diseases causes (cornea guttata) an accelerated loss of ECD and leads to a loss of corneal transparency. In these cases, only a corneal transplant surgery can restore visual function.

Surgery transplant on a patient is a heavy decision to make mainly based on ECD reserve evaluation and morphological criteria of cells. Unfortunately, a global quality control with a wide field image of corneal endothelial cells remains a challenge. This quality control is nevertheless crucial for patients as well as for corneal grafts stored in eye bankings. ${ }^{2}$ Indeed, only stored corneas with more than 2000 endothelial cells per $\mathrm{mm}^{2} \mathrm{can}$ be transplanted. ${ }^{3,4}$ Actual existing methods are non-contact specular microscopes ${ }^{5,6}$ with very a narrow field of observation as shown on Fig. 1(b) (approximatively $0.15 \mathrm{~mm}^{2}$ on the $80 \mathrm{~mm}^{2}$ of use). It is not up for the height of medical issues. In these both cases, a wide field imaging will definitely help clinicians and eye bankers to better assess the endothelial reserve of their patients and stored corneas. ${ }^{7,8}$

The aim of this projet is to advance the technology by developing a new generation of instruments which will combine the strength of specular microscopes: patient comfort with examination speed; and a large observation field of the endothelial cells of the cornea. This new technology could interest 500 eye banks in 200 countries.

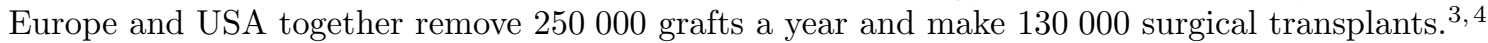

In the case of imaging an in-vivo patient's corneal endothelium, few constraints exist. Eye of patients cannot be touched by the optical system in order to avoid contaminations or injuries. In an other hand, this single monolayer is found very deeply in the cornea and epithelial reflectivity is 100 times higher than the one of endothelial. ${ }^{6,9}$ Also, as mentioned above, these cells diameter is about $20 \mu \mathrm{m}$, and a wide-field imaging system need a very high resolution to resolve each cell. With these constraints, we proposed to implement an optical sectioning system.

\section{THEORY}

The aim is then to optically isolate the corneal endothelial layer form its environment in order to remove corneal epithelial and stromal responses (see Fig.2(a)). In the case of a confocal microscope, ${ }^{10-12}$ adjacent planes out of the object focal plane of the microscope objective are filtered with a pinhole or a slit. In return, this pinhole limits the field size. An alternative method to achieve a wide-field optically sectioned image, is to change the illumination system ${ }^{13,14}$ and projecting a spatial-frequency grid pattern onto the object. The principle consist in having high contrasted illumination in the focal plane of the microscope objective. The contrast of the structured illumination is attenuated with defocus as shown on Fig.2 (b).

If the object to section is illuminated with a 1-D sinusoidal grid $S$ in the form:

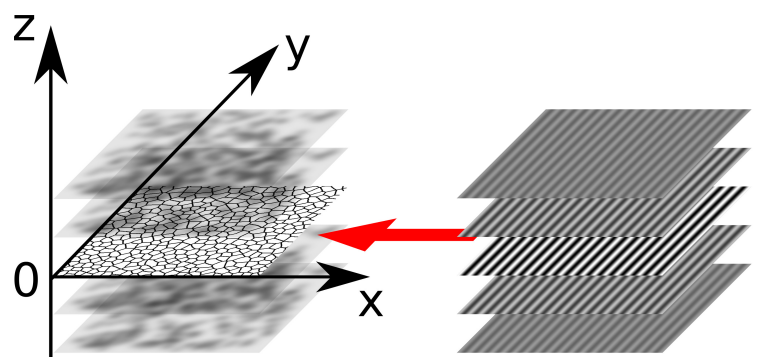

(a) (b)

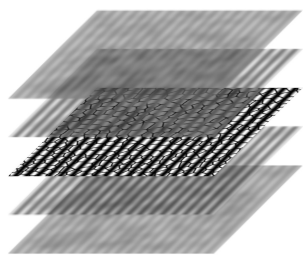

(c)

Figure 2. Principle of the structured illumination. (a) A perfect defined object in the focus plane is hidden by its environment. (b) A grid pattern illumination is contrasted in $z=0$ and blurred with $|z|$ increasing. (c) The object to isolate and the sinusoidal illumination are superimposed. 


$$
S=1+m \cos \left(2 \pi \nu x+\varphi_{0}\right),
$$

where $m$ denotes the visibility of the fringes and $\nu$ their spatial frequency, the final image obtained can be expressed as: ${ }^{13}$

$$
I=I_{0}+I_{c} \cos \left(\varphi_{0}\right)+I_{s} \sin \left(\varphi_{0}\right)
$$

$I_{0}$ corresponds of course to the conventional image without any modulation. $I_{s}$ and $I_{c}$ correspond to the signal wich contains the sinusoidal information, so the tiny volume to isolate from the environment. In this configuration, it is then possible to remove the grid pattern by calculating $I_{p}=\sqrt{I_{c}^{2}+I_{s}^{2}}$. $I_{p}$ corresponds to the part of the image where sinusoidal pattern is highly contrasted (as shown on Fig. 2(c)). An alternative easy way to form $I_{p}$ is to take three different images ${ }^{13,15} I_{1}, I_{2}$ and $I_{3}$ with 3 well-known relative spatial phases $\varphi_{0}=0, \varphi_{0}=2 \pi / 3$ $\varphi_{0}=4 \pi / 3$ respectively and calculate:

$$
\sqrt{\left(I_{1}-I_{2}\right)^{2}+\left(I_{2}-I_{3}\right)^{2}+\left(I_{1}-I_{3}\right)^{2}}
$$

wich is proportional to $I_{p}$.
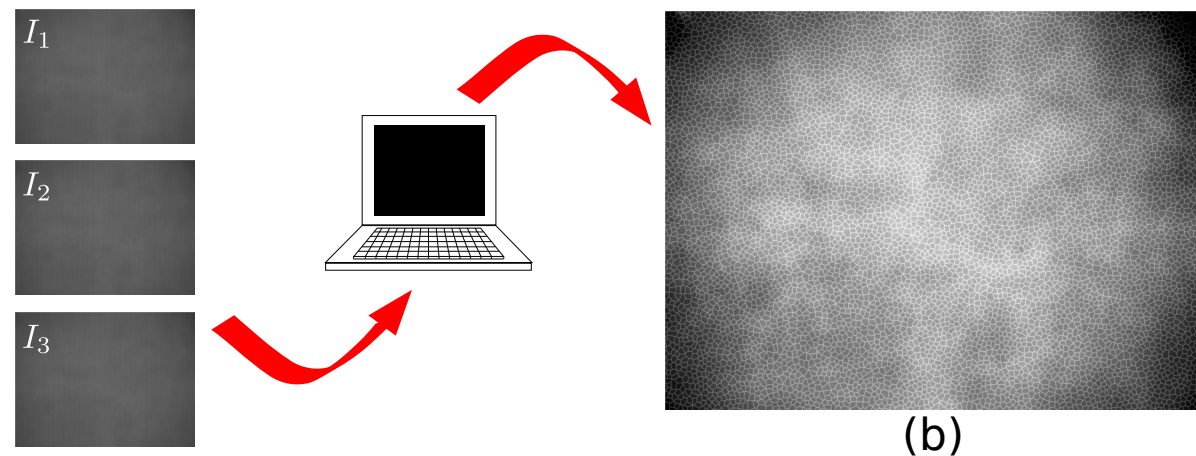

(b)

\section{(a)}

Figure 3. (a) Three images $I_{1}, I_{2}, I_{3}$ from a mosaic pattern multiplied by a sinusoidal illumination. Simulation parameters are: $N . A .=0.15, \lambda=0.63 \mu \mathrm{m}, \nu=1 / 13.89 \mu \mathrm{m}^{-1}, m=0.5$, and $\varphi_{0}=0,2 \pi / 30$ and $4 \pi / 3$ respectively for $I_{1}, I_{2}$ and $I_{3}$. (b) Reconstructed image from $I_{1}, I_{2}, I_{3}$ using eq. (3). Mosaic is clearly visible.

Numerical simulations have been performed in order to validate this method for our project. A large mosaic image multiplied by a sinusoidal pattern is calculated as shown on Fig. 2 (c). Contrast of the fringes taken for this simulation is $m=0.5$. Then, a stack of images representing surrounding scattering medias are multiplied by a sinusoidal pattern $S$ progressively defocused with $z$ using a first-order Bessel function:

$$
S=1+2 \frac{J_{1}\left(\pi N \cdot A \cdot{ }^{2} z / \lambda\right)}{\pi N \cdot A \cdot{ }^{2} z / \lambda} m \cos \left(2 \pi \nu x+\varphi_{0}\right),
$$

with N.A. the numerical aperture of the optical system, $\nu$ spatial frequency, $\lambda$ the wavelength. theses different images are added to the mosaic with a step of $10 \mu \mathrm{m}$ until reaching $z=500 \mu \mathrm{m}$, the thickness of cornea at the center. The total images obtained for the three different phases $\varphi_{0}$ are presented on Fig. 3 (a). These images are quite blurred and no mosaic is distinguishable. Fig. 3 (b) shows that the initial mosaic can easily be retrived using eq. (3). Simulation parameters are given in figure caption.

We hoped that structured illumination microscopy technique could allow us to bring up the weak signal of the endothelium hidden deep from its environment. It would help to get wide field images in order to get cells reserve of patients and stored corneas in eye banks. 


\section{EXPERIMENTAL SECTION}

The experimental set-up is presented on Fig. 4. The illumination of the specimens consists in a sinusoidal pattern (Edmound optics $72 \mathrm{lp} / \mathrm{mm}$ or $100 \mathrm{lp} / \mathrm{mm}$ ) projected with a red broad spectrum LED $(\lambda=630 \mathrm{~nm})$ by the lens $L$ in a $\Pi$ plane. $\Pi$ plane correspond to the part of the object to section. The magnification between the grid pattern and the $\Pi$ plane is $M=1$. A Z6-APO Leica microscope with a long working distance objective $2 \times$ $(W D=39 \mathrm{~mm})$ and a high numerical aperture $(N A=0.05$ to $N A=0.235)$ allows to observe specimens and a 16 bits camera captures images.

Illumination displacement in order to get the three different images is driven by a piezo controller and then a real-time reconstruction of images is achieved. Phases accuracy are calculated with a least square solution ${ }^{16}$ and a minimization of the Fourier transform of the reconstructed image. As the Fourier transform achieve its minimum, no residual lines appear on the reconstruted image.

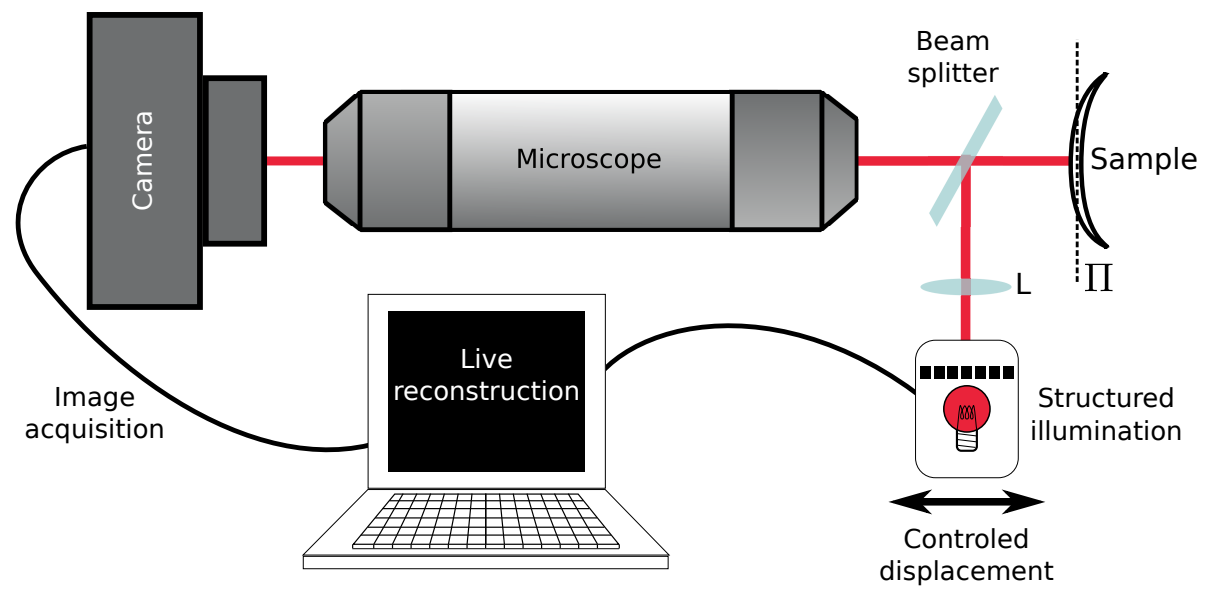

Figure 4. Sketch of the experimental set-up. The structured illumination is projected on the sample. Images are collected with a Macroscope Leica Z6-APO coupled to a camera. A computer pilots a live displacement of the illumination and computes a direct reconstruction.

\section{RESULTS AND DISCUSSION}

First experiments were conduced on a rabbit cornea stained with Alizarine Red and flat mounted between glass lamelas. These colored cells allow perfect visualization of endothelial cells as shown on Fig. 5 (a). Fig. 5 presents the corresponding reconstruted image in structured illumination imaging. Reconstructed image obtained exhibits clearly a better contrast. The field of this image is larger than $1 \times 1 \mu \mathrm{m}^{2}$. What can also be noted is that the parts of the object out of focus vanishes to black. The prototype provided well focused wide field images of this stained endothelium observed through the entire cornea, from the epithelial side.

Since then, non-colored endothelial cells of a flat monted human cornea have been observed. In more realistic cases, the weak signal of the endothelial cells is due to the very low index difference between the endothelium and the aqueous humour, respectively $n=1.377$ and $n=1.337$. Its seems difficult to obtain usefull images if a weak contrast does not already exist at this moment. More refinement are on going in order to obtain better images in the case of passing through the entire corena for the patient diagnostic.

The structured illumination microscopy allows to bring out patterns only found in the very focus plane of a microscope objective. Stored corneas present many folds because of their storage conditions. They are oedematous and opaque. In eye banking, ECD count can be made with images taken from endothelium side. In this case, structured illumination could make more easy cells counting varying $z$ direction and giving altitude information with a direct vanishing of information out of focus. 

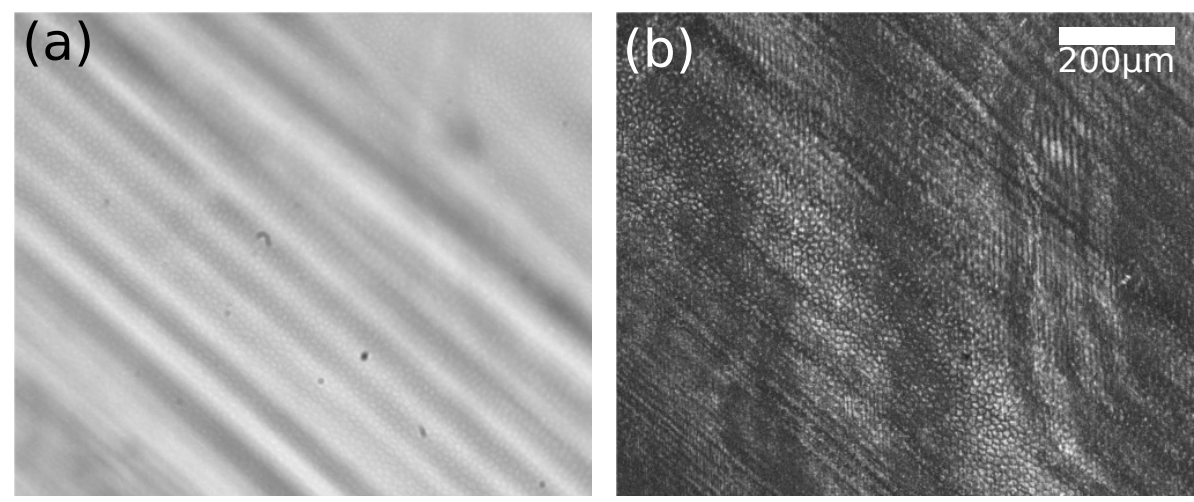

Figure 5. Flat mounted rabbit cornea with Alizarine red stained endothelium. (a) Conventional wide field image. (b) (b) Reconstructed image from structured illumination.

\section{CONCLUSION}

Despite a theoretical innovative concept, the non-contact wide field imaging of the endothelium for patient still remains a challenge. At this moment, no acceptable images have been obtained on fresh corneas passing through the entire cornea and further refinement are on going in order to get better images. In the case of stored corneas, it could help ECD counting by isolating tiny volumes and leads to a better 3-D reconstruction of the endothelial layer.

\section{ACKNOWLEDGMENTS}

This work was supported by the ANR, the French Research National Agency. Authors thank ANR for supporting this work, ANR-12-TECS-0004, CorImMo 3D, TecSan 2012.

\section{REFERENCES}

[1] Murphy, C., Alvarado, J., Jusrer, R., and Maglio, M., "Prenatal and Postnatal Cellularity of the Human Corneal Endothelium," Investigative Ophthalmology \& Visual Science 25(1), 312-322 (1984).

[2] Thuret, G., Manissolle, C., Acquart, S., Le Petit, J.-C., Maugery, J., Campos-Guyotat, L., Doughty, M. J., and Gain, P., "Is manual counting of corneal endothelial cell density in eye banks still acceptable? The French experience.," The British journal of ophthalmology 87, 1481-6 (Dec. 2003).

[3] Jones, G. L. a., Ponzin, D., Pels, E., Maas, H., Tullo, A. B., and Claerhout, I., "European Eye Bank Association.," tech. rep. (Jan. 2011).

[4] Eye Bank Association of America, "2012 Eye Bank Statistical Report," Tech. Rep. 202 (2013).

[5] Maurice, D. M., "Cellular membrane activity in the corneal endothelium of the intact eye," Experientia 24, 1094-5 (Nov. 1968).

[6] Koester, C. J., "Scanning mirror microscope with optical sectioning characteristics: applications in ophthalmology," Applied Optics 19, 1749-1757 (Jun 1980).

[7] Deb-Joardar, N., Thuret, G., Gavet, Y., Acquart, S., Garraud, O., Egelhoffer, H., and Gain, P., "Reproducibility of endothelial assessment during corneal organ culture: comparison of a computer-assisted analyzer with manual methods.," Investigative ophthalmology \& visual science 48, 2062-7 (May 2007).

[8] Campolmi, N., Acquart, S., He, Z., Gavet, Y., Jullienne, R., Naigeon, N., Bernard, A., Forest, F., Péoc'h, M., Thuret, G., and Gain, P., "Inherent errors of the fixed-frame counting method for corneal endothelial cell density in eye banks.," Cell and tissue banking (Nov. 2013).

[9] Hormire, J., [Instruments d'optique ophtalmique], Tec et Doc/Lavoisier (2010).

[10] Wilson, T., [Confocal Microscopy], Academic Press (1990). 
[11] Patel, D. V. and McGhee, C. N. J., "Contemporary in vivo confocal microscopy of the living human cornea using white light and laser scanning techniques: a major review.," Clinical 8 experimental ophthalmology 35(1), 71-88 (2007).

[12] Claxton, N. S., Fellers, T. J., and Davidson, M. W., "Laser scanning confocal microscopy."

[13] Neil, M. A. A., Juskaitis, R., and Wilson, T., "Method of obtaining optical sectioning by using structured light in a conventional microscope," Opt. Lett. 22, 1905-1907 (Dec. 1997).

[14] Neil, M. A. A., Juskaitis, R., and Wilson, T., "A light efficient optically sectioning microscope," Journal of Microscopy 189, 114-117 (Feb 1998).

[15] Chasles, F., Dubertret, B., and Boccar, A. C., "Optimization and characterization of a structured illumination microscope," Optics Express 15(24), 16130-16140 (2007).

[16] Schaefer, L. H., Schuster, D., and Schaffer, J., "Structured illumination microscopy: artefact analysis and reduction utilizing a parameter optimization approach," Journal of Microscopy 216(2), 165-174 (2004). 